\title{
The hospital anxiety and depression scale, in patients with multiple sclerosis
}

This article was published in the following Dove Press journal:

Neuropsychiatric Disease and Treatment

\author{
José Luís Pais-Ribeiro ${ }^{1,2}$ \\ Ana Martins da Silva ${ }^{3,4}$ \\ Estela Vilhena $^{5}$ \\ Inês Moreira ${ }^{3}$ \\ Ernestina Santos ${ }^{3,4}$ \\ Denisa Mendonça ${ }^{6}$
}

'William James Center for Research, ISPA - University Institute, Lisboa,

Portugal; ${ }^{2}$ Faculty of Psychology and

Education Sciences of the University of Porto (FPCEUP), Porto, Portugal;

${ }^{3}$ Neurology Department, Centro

Hospitalar do Porto-Hospital de

Santo António (CHP-HSA), Porto,

Portugal; ${ }^{4}$ Unit for Multidisciplinary

Research in Biomedicine (UMIB),

Abel Salazar Institute of Biomedical

Sciences-University of Porto

(ICBAS-UP), Porto, Portugal; ${ }^{5} 2 \mathrm{Ai}-$

Polytechnic Institute of Cávado and Ave, Barcelos, Portugal; 'Institute of

Public Health of the University of

Porto (ISPUP), Porto, Portugal
Correspondence: José Luís Pais Ribeiro Faculty of Psychology and Education Sciences of the University of Porto (FPCEUP), Rua Alfredo Allen, 4200-I 35 Porto, Portugal

Tel +35I 226079700

Fax +35I 226079725

Email jlpr@fpce.up.pt
Purpose: Multiple sclerosis (MS) is a long-lasting disabling disease with psychological implications. Hospital Anxiety and Depression Scale (HADS) is a questionnaire developed to screen anxiety and depression among patients in hospital settings. The objective of this report was to study the metric properties of the Portuguese version of HADS regarding MS.

Materials and methods: This was a cross-sectional study. Three hundred and eighty individuals with a diagnosis of MS, according to the revised McDonald criteria, were recruited from an outpatient Neuroimmunology Clinic of the city of Porto. Participants had a mean age of 40.04 years ( $\mathrm{SD}=10.86$ ), $63.9 \%$ of them were female. HADS consists of two subscales anxiety and depression - scored separately, with seven items each.

Results: The results of our study show the appropriateness of HADS for the identification of mood changes in people with MS and show good metric properties.

Conclusion: It seems to be a useful tool for the scrutiny of mood disorders in Portuguese patients with MS. The questionnaire is also sensitive to disease when compared to people with other severe illnesses, and with people without the disease.

Keywords: multiple sclerosis, depression, anxiety, HADS

\section{Introduction}

Multiple sclerosis (MS) is a chronic disease of the nervous system that produces various symptoms and may lead to severe disability with critical psychological implications. Population-based studies show that most patients are ambulatory even after many years of disease duration. ${ }^{1}$

The Hospital Anxiety and Depression Scale (HADS) is a brief self-reporting twodimensional questionnaire developed to screen for levels of anxiety and depression among patients in a general hospital setting. ${ }^{2,3}$ In a systematic review of the structure of the HADS, Cosco et $\mathrm{al}^{4}$ found divergences in the latent structure of the questionnaire and recommends caution because of the apparent lack of consistency between studies. This matter led to calls for the abandonment of the HADS. ${ }^{5}$ In response to these conclusions, a meta confirmatory factor analysis $(\mathrm{CFA})^{6}$ provides support for the bifactor model but suggests caution in the use of the scale. Stern ${ }^{7}$ confirms that HADS is appropriate for initial diagnosis and to track the progression of psychological symptoms. National Institute for Health and Care Excellence (section 1.3.2, point 1.3.2.3 $)^{8}$ had recommended the scale for the diagnosis of depression and anxiety.

HADS is one of the most widely used questionnaires among patients with neurological illnesses, and it is useful for assessing patients who tire easily or have limited concentration spans. ${ }^{9}$ Watson et $\mathrm{al}^{10}$ confirm that HADS is an appropriate screening measure for people with MS. Litster et $\mathrm{al}^{11}$ in a systematic review about the assessment 
of anxiety in people with MS state that HADS-A shows promise as an applicable measure for this population. In the evaluation of depression in people with MS, a systematic review of Hind et $\mathrm{al}^{12}$ asserts that HADS-D is a useful screening instrument.

However, research alerts about possible problems in the translated versions and cross-cultural use of the HADS and claims that rates of anxiety and depression using the same cut point across languages and culture may be wrong or subject to critical scrutiny. ${ }^{13}$

In a previous study, ${ }^{14}$ the metric properties of a Portuguese version of HADS were described when applied to 1,322 individuals with chronic diseases, namely, cancer, stroke, epilepsy, coronary heart disease, morbid obesity, diabetes, myotonic dystrophy, obstructive sleep apnea, depression, and a non-disease group.

The core objective of the present report was to describe the metric properties of the Portuguese version of HADS among people with MS.

\section{Materials and methods Participants}

We analyzed a consecutive sample of 380 individuals (63.9\% female, $36.1 \%$ male; mean age $40.04 \pm 10.86$ years; range: 16-71 years) with MS according to the revised McDonald criteria, from the outpatient Neuroimmunology Clinic at a Central Hospital in Porto, Portugal.

\section{Measure HADS}

HADS consists of two subscales, one measuring anxiety, with seven items, and another measuring depression, with seven items, which score separately. Each item was answered by the patient on a 4-point (0-3) scale, so the possible scores ranged from 0 to 21 for each of the two subscales, taking 2-5 minutes to complete. ${ }^{2,3}$ The HADS manual indicates that a score between 0 and 7 is "normal," between 8 and 10 "mild," between 11 and 14 "moderate," and between 15 and 21 "severe." Some authors propose a different classification. In a study with a Brazilian sample (Portuguese-Brazilian language), Botega et $\mathrm{al}^{15}$ proposed a cutoff point of 8/9 for anxiety and depression scales. Other studies suggest that the recommended cutoff scores for the HADS may result in under-reporting of psychiatric morbidity in different chronic diseases. ${ }^{16}$

The original authors post a score of $\geq 11$ as indicating the probable presence ("caseness") of a mood disorder, and a score of 8-10 being just suggestive of the presence of the respective state. Based on the score of $\geq 8$, Honarmand and Feinstein's research ${ }^{17}$ confirms the usefulness of the HADS as a marker of major depression and generalized anxiety disorder in MS patients. In a review of different screening measures to identify anxiety disorders in MS, Litster et al ${ }^{11}$ conclude that HADS is the best available tool for detecting the symptoms of anxiety in individuals with MS.

\section{Procedure}

The study used a cross-sectional design with all measures taken at the same time. Ethical approval for the study was given by the ethical committee at the hospital St. Antonio, Porto, according to hospital rules and Portuguese law. Namely, signed informed consent was obtained before participation in the study in accordance with the Declaration of Helsinki. A registered psychologist administered the tests individually during the patient routine visit to the hospital.

\section{Statistical analysis}

To identify the factorial structure of the scale, in this group of MS patients, exploratory factor analysis was applied. Moreover, to test the hypothesized two model dimensions, CFA was used.

\section{Results}

\section{Exploratory factorial validity}

Exploratory factor analysis using principal component analysis, oblimin rotation method with Kaiser normalization for the 14 items, showed two components: the first one associated with the seven anxiety items and the second one related to the seven items from depression. The total variance of the solution explains $49.07 \%$ (39.26\% for the first component). Loadings on the component that they belong to are in bold format in Table 1. All items load on the dimension they belong to.

Differences in loadings between the component the item belongs to and the component it does not belong to are above 0.15 points, except for item 14. Table 1 shows loadings on the dimensions above 0.35 . Internal consistency, using Cronbach's alpha, for the two dimensions is good; 0.80 for anxiety and 0.81 for depression.

\section{CFA}

CFA is a theory-testing model as opposed to a theory-generating method such as exploratory factor analysis. Byrne ${ }^{20}$ suggests that there is a wide array of fit indexes from which to choose, but that only one or two needs be reported. Maximum likelihood CFA, using EQS V6.121 was used to test the two-factor 
Table I Exploratory factor analysis - presenting loadings above 0.35

\begin{tabular}{|l|l|l|}
\hline & Anxiety & Depression \\
\hline HADSI & 0.74 & 0.39 \\
\hline HADS2 & & 0.78 \\
\hline HADS3 & 0.75 & 0.40 \\
\hline HADS4 & 0.49 & $\mathbf{0 . 7 9}$ \\
\hline HADS5 & 0.74 & 0.40 \\
\hline HADS6 & 0.53 & 0.79 \\
\hline HADS7 & 0.60 & 0.43 \\
\hline HADS8 & & 0.53 \\
\hline HADS9 & 0.65 & 0.43 \\
\hline HADSI0 & 0.35 & 0.72 \\
\hline HADSII & 0.52 & \\
\hline HADSI2 & 0.36 & 0.71 \\
\hline HADSI3 & 0.71 & 0.44 \\
\hline HADSI4 & 0.46 & 0.50 \\
\hline
\end{tabular}

Notes: Extraction method: principal component analysis. Rotation method: oblimin with Kaiser normalization. Bold figures represent that the item belongs to that factor or dimension in coincidence with the higher loading.

hypothesized model. Results show a LISREL goodness-of-fit index of 0.90 and a root mean square error of approximation (RMSEA) of 0.08 (90\% confidence interval of RMSEA, between 0.07 and 0.10 ), a result that suggests an acceptable fit of the two dimensions model. ${ }^{22,23}$ It is similar to other reported studies. ${ }^{24}$

\section{Comparison between groups}

Independent $t$-tests were used to compare the anxiety and depression subscale scores between MS patients and the other disease groups from previous studies with Portuguese samples. ${ }^{14}$ Comparison of the results of the previous study and the MS group is presented in Table 2.

HADS mean values obtained in the present study for people with MS are higher [anxiety: $7.94(\mathrm{SD}=4.31)$, depression: $5.63(\mathrm{SD}=4.01)]$ than those reported in other studies for both the dimensions, ${ }^{25,26}$ but lower if compared with other studies. ${ }^{27}$ Correlation between anxiety and depression are statistically significant $[r(380)=0.60]$. Correlations between age and anxiety are not statistically significant. However, correlations between age and depression is statistically significant $[r(375)=0.30, P<0.001]$, also different from the study of Jones et al, ${ }^{27}$ which did not find statistically significant correlations between age and depression and report a statistically significant correlation between age and anxiety.

Differences between gender for anxiety and depression are statistically significant at the $P$ level $<0.001$, with females showing higher mean values than males (anxiety 8.72 vs 6.57 and depression 6.24 vs 4.55 ). These values are different from the ones reported by Jones et $\mathrm{al}^{27}$ which, for depression, report higher values in men: these differences are also reported in other studies in different languages and problems. $^{28}$

In the present study, for depression, $8.2 \%$ of the participants exhibited a score of $\geq 11$ and $23.4 \%$ a score of $\geq 8$, and for anxiety, $21.6 \%$ of the participants presented a score of $\geq 11$ and $41.6 \%$ a score of $\geq 8$. These values are similar to those reported by Siegert and Abernethy. ${ }^{29}$ For depression by gender, $9.9 \%$ of females exhibit a value of $\geq 11$ and $28.8 \%$ a value of $\geq 8$, and $5.1 \%$ of males exhibit a value of $\geq 11$ and $15.9 \%$ a value of $\geq 8$. For anxiety, $28.5 \%$ of males exhibit a value of $\geq 8$ and $16.1 \%$ a value of $\geq 11$ and $24.7 \%$ of females exhibit a value of $\geq 11$ and $49 \%$ a value of $\geq 8$. These scores suggests a possible presence of mood disorder for most of the sample for anxiety.

When comparing the MS group with other chronic diseases, more statistically significant differences are found for depression than for anxiety. For anxiety, no statistically

Table 2 Anxiety and depression means by disease group, and statistically significant differences with MS patients

\begin{tabular}{|c|c|c|c|c|c|c|c|}
\hline \multirow[t]{2}{*}{ Disease group } & \multirow[t]{2}{*}{$\mathbf{n}$} & \multicolumn{3}{|l|}{ Anxiety } & \multicolumn{3}{|l|}{ Depression } \\
\hline & & $M(S D)$ & $t$ & $P$-value & $M(S D)$ & $t$ & $P$-value \\
\hline No disease & 22 & $7.81(4.72)$ & 0.09 & 0.93 & $3.22(3.02)$ & 2.74 & $<0.01$ \\
\hline Cancer & 98 & 9.18 (4.74) & -2.59 & 0.009 & $5.89(4.34)$ & -0.57 & 0.56 \\
\hline Stroke & 252 & $10.53(4.36)$ & -7.50 & $<0.001$ & $9.19(4.63)$ & -10.13 & $<0.001$ \\
\hline Epilepsy & 100 & $8.59(4.17)$ & -1.45 & 0.14 & $5.18(4.18)$ & 0.97 & 0.33 \\
\hline Diabetes & 316 & $8.18(4.53)$ & -0.86 & 0.39 & $5.46(4.34)$ & 0.52 & 0.60 \\
\hline Cardiac coronary disease & 274 & $8.41(3.86)$ & -1.57 & 0.11 & 5.53 (3.99) & 0.31 & 0.75 \\
\hline Morbid obesity & 190 & $10.52(4.35)$ & -6.85 & $<0.001$ & $7.28(4.35)$ & -4.45 & $<0.001$ \\
\hline Obstructive sleep apnea & 31 & $6.87(3.39)$ & 1.31 & 0.19 & $3.83(2.66)$ & 2.42 & 0.01 \\
\hline Depression & 20 & 11.00 (3.91) & -3.18 & 0.002 & $12.90(3.7 \mid)$ & -7.87 & $<0.00 \mathrm{I}$ \\
\hline Myotonic dystrophy & 18 & 7.27 (4.07) & 0.61 & 0.54 & $7.22(4.14)$ & -1.63 & 0.10 \\
\hline Multiple sclerosis & 380 & $7.94(4.31)$ & - & - & $5.63(4.01)$ & - & - \\
\hline
\end{tabular}

Abbreviations: $M$, mean; MS, Multiple sclerosis; $P$, level of statistical significance; $t$, test for independent samples. 
significant differences were found between the MS group and the non-disease group. For depression, statistically significant differences $[t(390)=2.74, P<0.01]$ were present, showing that the MS group had higher values $(M=5.63)$ than the non-disease group ( $M=3.22)$. Comparing with the depression disease group, the magnitude of values is much higher for the depression group. These results seem to confirm the results of a review by Siegert and Abernethy, ${ }^{29}$ which states that depression is common in MS.

Statistically significant differences were found when anxiety and depression scores were compared between MS patients and those with other diseases (Table 2). Compared with the depression group, MS patients showed statistically significant lower values in anxiety $[t(388)=3.18, P<0.01]$ and in depression $[t(388)=7.87, P<0.001]$.

Furthermore, similar differences were found in anxiety scores in cancer, stroke, and morbid obesity patients, and in depression scores in stroke and morbid obesity patients. MS patients had significantly higher depression scores than obstructive sleep apnea patients.

Correlations between age and anxiety and depression show a non-significant association for anxiety and a statistically significant association - though moderate - for depression $[r(365)=0.29, P<0.0001]$, suggesting that age is not associated with anxiety and depression. The correlation between anxiety and depression $[r(380)=0.60, P<0.0001]$ is similar to the Portuguese adaptation study ${ }^{14,19}$ and other reported studies.

\section{Discussion and conclusion}

International research on HADS shows that it is a useful tool to evaluate anxiety and depression in people suffering from different diseases, including MS. In an extensive study, Dahl et $\mathrm{al}^{30}$ show that anxiety and depression occur more frequently in MS patients than in the general population. Because anxiety and depression seem to be common in people with $\mathrm{MS},{ }^{17}$ it seems appropriate to screen for possible mood elevation in these patients. Our study identifies, for depression, essential differences between people with MS and people without diseases, and people with a diagnostic of depression and people with MS, suggesting the existence of a sensibility that differentiates between people with MS and people with and without the diagnosis of depression when using HADS dimensions.

The results of our report confirm the findings from international research and suggest that the Portuguese HADS version behaves similarly. It seems to be a useful tool for the scrutiny of mood in Portuguese patients with MS as it is for other diseases. Remember that in the original development of the scale, because scores can be affected by the physical illness of the patient, authors eliminated items relating simultaneously to emotional disorder and physical disorder. Items selected were based solely on the anxiety and depression symptoms. ${ }^{3}$ Because items are independent of the characteristics of the disease, people with different diseases, and people without diseases, may have the same level of emotional disturbance, due to some other life events than the ones related to the disease (symptoms and inherent treatment). HADS is a useful tool to help people in medical settings cope with the disease and reduce emotional distress.

The objective of the research was to report the metric properties and the dimensionality of HADS because recent research suggests for example "No further research needed: abandoning the Hospital and Anxiety Depression Scale."5 while others suggests a different number of dimensions of the scale. ${ }^{4,24,31,32}$ However, more profound research recommends that the two-factor solution seems to be the most appropriate solution for $\mathrm{HADS}^{6}$ together with large population studies. ${ }^{18}$ Other research suggests that HADS may be challenging to translate and that translated versions of the HADS may not be attainable. ${ }^{13}$ However, different languages found that the HADS is appropriate for use and found the same factorial solution for the HADS. ${ }^{14,33}$ In the present study, the results suggest that the translated version behaves like other different languages translations. The psychometric properties are good, and a clinimetric analysis shows sensitivity when we compare people with different chronic diseases to people without any condition. In conclusion, the HADS seems to be a useful instrument to be included in the study of people with MS.

\section{Disclosure}

The authors report no conflicts of interest in this work.

\section{References}

1. Nortvedt MW, Riise T, Maeland JG. Multiple sclerosis and lifestyle factors: the Hordaland Health Study. Neurol Sci. 2005;26(5):334-339.

2. Snaith RP, Zigmond AS. The Hospital Anxiety and Depression Scale Manual. Windsor: Nfer-Nelson; 1994.

3. Zigmond AS, Snaith RP. The hospital anxiety and depression scale. Acta Psychiatr Scand. 1983;67(6):361-370.

4. Cosco TD, Doyle F, Ward M, McGee H. Latent structure of the Hospital Anxiety and Depression Scale: a 10-year systematic review. J Psychosom Res. 2012;72(3):180-184.

5. Coyne JC, van Sonderen E. No further research needed: abandoning the Hospital and Anxiety Depression Scale (HADS). J Psychosom Res. 2012;72(3):173-174.

6. Norton S, Cosco T, Doyle F, Done J, Sacker A. The Hospital Anxiety and Depression Scale: a meta confirmatory factor analysis. J Psychosom Res. 2013;74(1):74-81. 
7. Stern AF. The Hospital Anxiety and Depression Scale. Occup Med (Lond). 2014;64(5):393-394.

8. National Institute for Health and Care Excellence. Common mental health problems: identification and pathways to care. Clinical guideline [CG 123]; 2011. Available from: https://www.nice.org.uk/guidance/ cg123. Accessed October 2017.

9. Murrell R. Quality of life and neurological illness: a review of the literature. Neuropsychol Rev. 1999;9(4):209-229.

10. Watson TM, Ford E, Worthington E, Lincoln NB. Validation of mood measures for people with multiple sclerosis. Int J MS Care. 2014; 16(2):105-109.

11. Litster B, Fiest KM, Patten SB, et al; CIHR Team "Defining the Burden and Managing the Effects of Psychiatric Comorbidity in Chronic Immunoinflammatory Disease". Screening tools for anxiety in people with multiple sclerosis: a systematic review. Int J MS Care. 2016;18(6):273-281.

12. Hind D, Kaklamanou D, Beever D, et al. The assessment of depression in people with multiple sclerosis: a systematic review of psychometric validation studies. BMC Psychiatry. 2016;16:278.

13. Maters GA, Sanderman R, Kim AY, Coyne JC. Problems in crosscultural use of the hospital anxiety and depression scale: "no butterflies in the desert". PLoS One. 2013;8(8):e70975.

14. Pais-Ribeiro J, Silva I, Ferreira T, Martins A, Meneses R, Baltar M. Validation study of a Portuguese version of the Hospital Anxiety and Depression Scale. Psychol Health Med. 2007;12(2):225-235; quiz 235-237.

15. Botega NJ, Bio MR, Zomignani MA, Garcia C Jr, Pereira WA. Transtornos do humor em enfermaria de clínica médica e validação de escala de medida (HAD) de ansiedade e depressão [Mood disorders among medical in-patients: a validation study of the hospital anxiety and depression scale (HAD). Rev Saúde Pública. 1995;29(5):355-363. Portuguese.

16. Love AW, Kissane DW, Bloch S, Clarke D. Diagnostic efficiency of the Hospital Anxiety and Depression Scale in women with early stage breast cancer. Aust N Z J Psychiatry. 2002;36(2):246-250.

17. Honarmand K, Feinstein A. Validation of the Hospital Anxiety and Depression Scale for use with multiple sclerosis patients. Mult Scler. 2009;15(12):1518-1524

18. Mykletun A, Stordal E, Dahl AA. Hospital Anxiety and Depression (HAD) scale: factor structure, item analyses and internal consistency in a large population. Br J Psychiatry. 2001;179(1):540-544.

19. Silva L, Pais-Ribeiro J, Cardoso H. Contributo para a adaptação da Hospital Anxiety and Depression Scale população portuguesa com a doença crónica [Contribution to the adaptation of the Hospital Anxiety and Depression Scale to the Portuguese population with chronic disease]. Psychologica. 2006;41:193-204. Portuguese.
20. Byrne BM. Factor analytic models: viewing the structure of an assessment instrument from three perspectives. $J$ Pers Assess. 2005;85(1): $17-32$.

21. Bentler PM, Wu EJC. EQS/Windows User's Guide. Los Angeles: BMDP Statistical Software; 1995.

22. Bentler PM, Bonett DG. Significance tests and goodness of fit in the analysis of covariance structures. Psychol Bull. 1980;88(3):588-606.

23. Browne MW, Cudeck R. Alternative ways of assessing model fit. In: Bollen KA, Long JS, editors. Testing Structural Equation Models. Newbury Park: Sage; 1993:136-162.

24. Barth J, Martin CR. Factor structure of the Hospital Anxiety and Depression Scale (HADS) in German coronary heart disease patients. Health Qual Life Outcomes. 2005;3:15.

25. Fournier M, de Ridder D, Bensing J. How optimism contributes to the adaptation of chronic illness. A prospective study into the enduring effects of optimism on adaptation moderated by the controllability of chronic illness. Pers Individ Dif. 2002;33(7):1163-1183.

26. Montazeri A, Vahdaninia M, Ebrahimi M, Jarvandi S. The Hospital Anxiety and Depression Scale (HADS): translation and validation study of the Iranian version. Health Qual Life Outcomes. 2003;1:14.

27. Jones KH, Ford DV, Jones PA, et al. A large-scale study of anxiety and depression in people with Multiple Sclerosis: a survey via the web portal of the UK MS Register. PLoS One. 2012;7(7):e41910.

28. Bocéréan C, Dupret E. A validation study of the Hospital Anxiety and Depression Scale (HADS) in a large sample of French employees. BMC Psychiatry. 2014;14:354.

29. Siegert RJ, Abernethy DA. Depression in multiple sclerosis: a review. J Neurol Neurosurg Psychiatry. 2005;76(4):469-475.

30. Dahl OP, Stordal E, Lydersen S, Midgard R. Anxiety and depression in multiple sclerosis. A comparative population-based study in NordTrøndelag County, Norway. Mult Scler. 2009;15(12):1495-1501.

31. Amini P, Maroufizadeh S, Omani Samani R. Evaluating the factor structure, item analyses, and internal consistency of hospital anxiety and depression scale in Iranian infertile patients. Int J Reprod Biomed (Yazd). 2017;15(5):287-296.

32. Dunbar M, Ford G, Hunt K, Der G. A confirmatory factor analysis of the Hospital Anxiety and Depression scale: comparing empirically and theoretically derived structures. Br J Clin Psychol. 2000;39(Pt 1): 79-94.

33. Iani L, Lauriola M, Costantini M. A confirmatory bifactor analysis of the Hospital Anxiety and Depression Scale in an Italian community sample. Health Qual Life Outcomes. 2014;12:84.
Neuropsychiatric Disease and Treatment

\section{Publish your work in this journal}

Neuropsychiatric Disease and Treatment is an international, peerreviewed journal of clinical therapeutics and pharmacology focusing on concise rapid reporting of clinical or pre-clinical studies on a range of neuropsychiatric and neurological disorders. This journa is indexed on PubMed Central, the 'PsycINFO' database and CAS,

\section{Dovepress}

and is the official journal of The International Neuropsychiatric Association (INA). The manuscript management system is completely online and includes a very quick and fair peer-review system, which is all easy to use. Visit http://www.dovepress.com/testimonials.php to read real quotes from published authors. 